\title{
Method of Parallel Information Object Search in Unified Information Spaces
}

\author{
Alexander Dodonov \\ Institute of Problems of Information Registration of the National Academy of Sciences of Ukraine, Deputy Director for \\ Scientific Research, 03113, Kiev, Ukraine \\ E-mail: dodonovua@gmail.com
}

\section{Vadym Mukhin}

National Technical University of Ukraine "Igor Sikorsky Kiev Polytechnic Institute", Department of the mathematical methods of system analysis, 03056, Kiev, Ukraine

E-mail: v.mukhin@kpi.ua

\section{Valerii Zavgorodnii}

State University of Infrastructure and Technologies, Department of the Information Technologies and Design, 04071, Kiev, Ukraine

E-mail: zavgorodniivalerii@gmail.com

\section{Yaroslav Kornaga}

National Technical University of Ukraine "Igor Sikorsky Kiev Polytechnic Institute", Computer systems department, 03056, Kiev, Ukraine

E-mail: y.kornaga@kpi.ua

\section{Anna Zavgorodnya}

State University of Infrastructure and Technologies, Department of the Information Technologies and Design, 04071, Kiev, Ukraine

E-mail: annzavgorodnya@gmail.com

\section{Oleg Mukhin}

National Technical University of Ukraine "Igor Sikorsky Kiev Polytechnic Institute", Department of the mathematical methods of system analysis, 03056, Kiev, Ukraine

E-mail: o.mukhin01@gmail.com

Received: 13 April 2021; Accepted: 21 May 2021; Published: 08 August 2021

\begin{abstract}
The article describes the concept of a unified information space and an algorithm of its formation using a special information and computer system. The process of incoming object search in a unified information space is considered, which makes it possible to uniquely identify it by corresponding features. One of the main tasks of a unified information space is that each information object in it is uniquely identified. For this, the identification method was used, which is based on a step-by-step analysis of object characteristics. The method of parallel information object search in unified information spaces is proposed, when information object search will be conducted independently in all unified information spaces in parallel. Experimental studies of the method of parallel information object search in unified information spaces were conducted, on the basis of which the analysis of efficiency and incoming objects search time in unified information spaces was carried out. There was experimentally approved that the more parameters that describe the information object, the less the time of object identification depends on the length of the interval. Also, there was experimentally approved that the efficiency of the searching of the incoming objects in unified information spaces tends to a directly proportional relationship with a decrease in the length of the interval and an increase in the number of parameters, and vice versa.
\end{abstract}

Index Terms: Unified information space, features, parameters, information object, search method. 


\section{Introduction}

A unified information space is a set of tools that ensure the unity of presentation, processing and interpretation of information about information objects. The purpose of creating a single information space is to provide access to unified information without limiting location and time.

To form a unified information space, it is necessary to implement a single data entry, store data in single formats and exchange information between all information objects. Information about objects in a unified information space changes dynamically.

Creation of a unified information space is intended to provide all users with a single description of information objects so that all unified information space users perceive the same information object in the same way. This characteristic is the main feature of a unified information space.

The purpose of the article is to propose the method of parallel information object search in unified information spaces.

To achieve the main purpose of the article, it is necessary to solve the following tasks:

- to develop an algorithm for the formation of a unified information space;

- the develop a method of parallel search for an information object in unified information spaces, when the search for an information object will be independent in the all unified information spaces;

- to perform the efficiency and the time of searching analysis for incoming objects in a unified information space based on the suggested method.

\section{Literature Survey}

Significant contributions to information space studies were made by famous scientists V.S. Pirumov, V.D. Popov, G.G. Pocheptsov, G.V. Grachev, I.K. Melnik, S.A. Modestov, S. Datsyuk, V.A. Kopylov, V.G. Krysko, S. Parinov, L. Malkov, V.G. Mashlykin, M.I. Abdurakhmanov, V.A. Barishpolets, V.L. Manilov, S.P. Rastorguev, S.E. Zuev, V.B. Veprintsev.

In the article [1], content of information objects in the information field is analyzed, their features are described, and information objects typification is performed.

The article [2] examines the state of scientific research in the field of the emergence, formation and development of the educational space concept. The space is considered in its various scientific aspects. The concept of "a unified information educational space" is formulated, its organizational and technological components are given.

In the article [3], the author reveals the concept of "a unified information space" through such categories as "information space", "information", "unified space", and also highlights the criteria, components, objects and subjects of a unified information space, determines its parameters.

The article [4] proposes the approach to solving the problem of identifying information objects in automated information systems designed for collecting, storing and processing data that have a large number of nodes and receive data from various sources. To solve such problems, it is proposed to identify information objects, that is, to define a set of information objects that are, with a certain probability, the same object. It can be seen that the problem of finding connections between information objects is closely related to the identification problem, since the probability of two information objects' identity increases if we find a connection of each of them, for example, with a third information object. The correlation search method is proposed for identifying the relationship between information objects.

The article [5] discusses the principles of creating a unified information space of corporate systems, which combines heterogeneous components. The main and most complex aspects of creating a unified information space are highlighted, problems that arise during creation are considered, ways of solving them and possibility of creating appropriate tools are indicated.

To assess reliability of a unified information space functioning, the article [6] proposes the methodology for constructing its model, which includes seven main groups of assessed elements.

In the article [7], information object identification based on a step-by-step feature analysis in a unified information space was considered, which made it possible to uniquely determine the input information object by corresponding features.

In the articles [8-18] are presented the different approaches to the analytical assessments of the parameters of distributed computer systems and of the information spaces.

In this paper, it is proposed to use a set of unified information spaces and to carry out the process of incoming object identifying according to corresponding features. 


\section{Algorithm for the Formation of a Unified Information Space}

Figure 1 shows a general scheme of a unified information spaces set existence, such as UIS $_{1}$, UIS $_{2}, \ldots$, UIS $_{\mathrm{m}}$, where $m$ is the number of unified information spaces.

Each of unified information spaces has its own set of information objects: $\mathrm{IO}_{1}, \mathrm{IO}_{2}, \ldots, \mathrm{IO}_{\mathrm{K}}$. Each of them has a set of $\mathrm{P}_{1}, \mathrm{P}_{2}, \ldots, \mathrm{P}_{\mathrm{n}}$ features, where $k$ is the number of information objects, and $n$ is the number of information object features. That is, $\mathrm{IO}_{\mathrm{K}}\left(\mathrm{P}_{1}, \mathrm{P}_{2}, \ldots, \mathrm{P}_{\mathrm{n}}\right)$.

Information objects features must be in a single format and their number must be the same. Each single information space can contain the same information objects, for example $\mathrm{UIS}_{1}\left(\mathrm{IO}_{1}\right)=\mathrm{UIS}_{\mathrm{m}}\left(\mathrm{IO}_{\mathrm{k}}\right)$.

Taking into account the above, we will present the algorithm for unified information space formation based on an information computer system:

1. A computer system is a distributed system for converting information that comes from different sources and, as a rule, in different formats, into a single set of information objects features, by which unified information space users can uniquely identify an information object.

2. The point of user entry into the computer system is highlighted. There can be many entry points like this.

3. Regardless of the entry point, a unified software and hardware space is formed for the user.

4. A set of software services is available to the user from any entry point.

5. Each user has an account which records often used software services, as well as user's actions, including ones towards specific services.

6. User accounts are stored remotely and can be accessed from various entry points.

7. When a user enters through the entry point, its environment is configured, that is, the often-used services are selected, and his actions towards specific services are analyzed.

8. As a result, the user sees a computer system as a unified space, regardless of the current entry point.

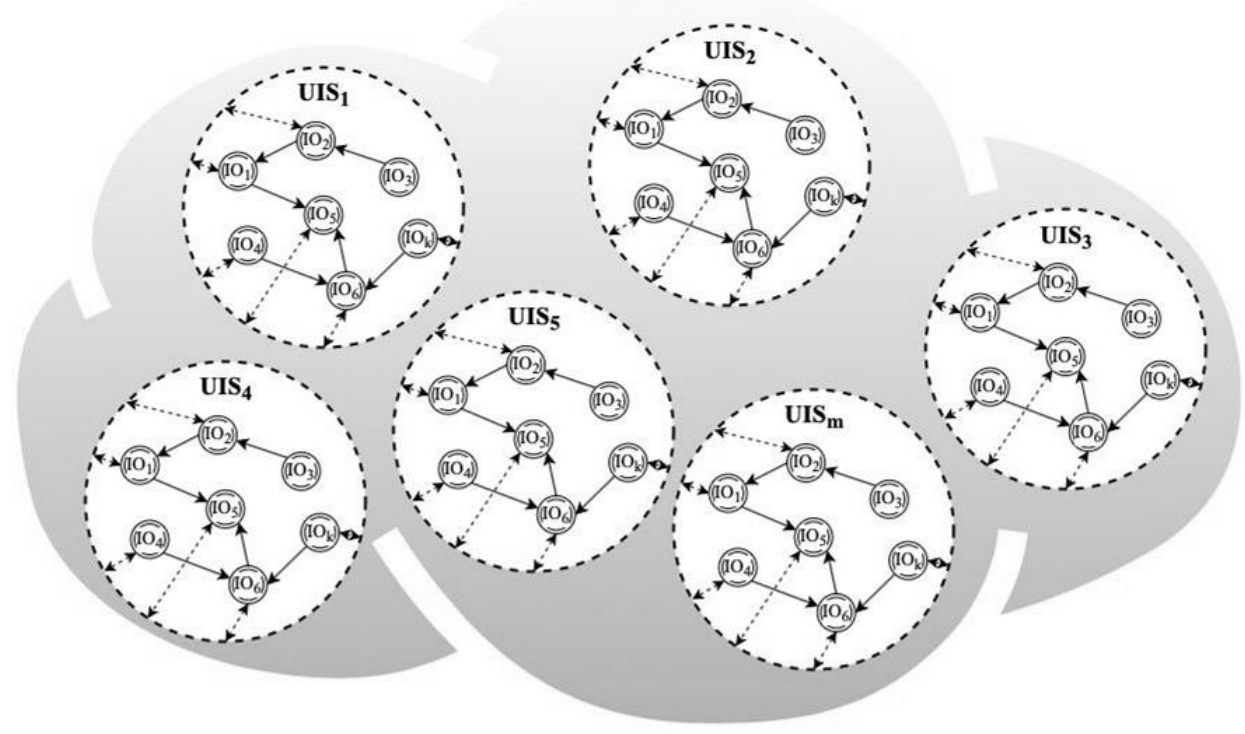

Fig.1. A general scheme of a unified information spaces set existence.

One of the main tasks of a unified information space is that each information object in it is uniquely identified.

Information object identification in a unified information space makes it possible to uniquely identify it according to corresponding features. For this, an identification method can be used, which is based on a step-by-step object features analysis.

External information sources for a unified information space represent objects $\mathrm{O}_{1}, \mathrm{O}_{2}, \ldots, \mathrm{O}_{\mathrm{i}}$ in different ways, where $i$ is the number of objects used by the information space. Information about these objects in the form of a features values set is obtained by reading them using sensors.

In a unified information space, there are many information objects $\mathrm{IO}_{1}, \mathrm{IO}_{2}, \ldots, \mathrm{IO}_{\mathrm{K}}$, which have a set of features $\mathrm{P}_{1}$, $\mathrm{P}_{2}, \ldots \mathrm{P}_{\mathrm{n}}$, where $k$ is the number of information objects, and $n$ is the number of an information object features. That is, $\mathrm{IO}_{\mathrm{K}}\left(\mathrm{P}_{1}, \mathrm{P}_{2}, \ldots, \mathrm{P}_{\mathrm{n}}\right)$. So, each information object has the same number of features, if some features are absent, then the feature value is NONE.

In a unified information space, there are no two absolutely identical information objects: $\mathrm{IO}_{1} \neq \mathrm{IO}_{2} \neq \mathrm{IO}_{3} \neq \ldots \neq$ $\mathrm{IO}_{\mathrm{K}}$. In this regard, a unified information space should act as a help system that will be constantly updated and trained. 
For all this, we need to go through several stages:

1. Form a unified information space with a set of unique information objects, that is, to recognize incoming objects without reference to a specific object.

2. Read the characteristics of the object using sensors, which are a kind of meters. If for some reason the sensor failed to do this, the information about this parameter will be absent - the value is NULL.

3. The system receives an object $\mathrm{O}_{\mathrm{i}}$ with a certain set of features, sensors must read its values, and a unified information space must uniquely determine whether there is an information object with exactly the same values of features in the unified information space - thus, to identify the object.

\section{Method of Parallel Information Object Search in Unified Information Spaces}

The essence of this method is that information object search will be conducted independently in parallel in all unified information spaces. The structure of in unified information spaces is shown in Figure 2.

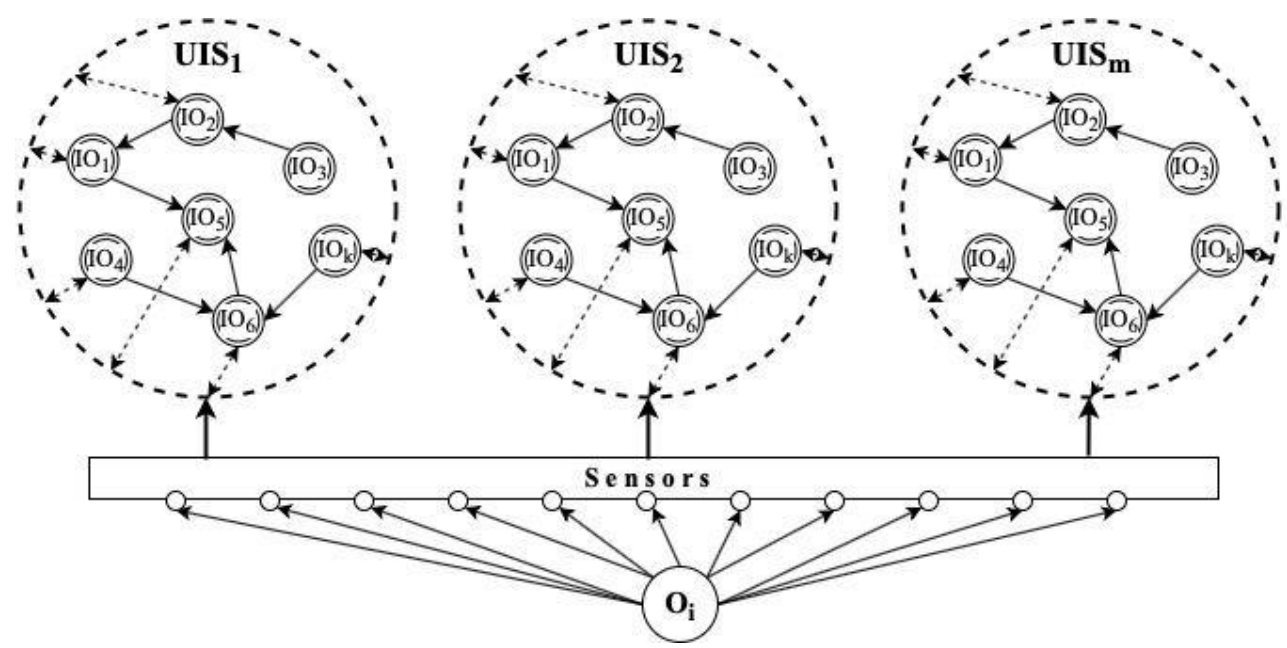

Fig.2. Structure of parallel information object search in unified information spaces.

The algorithm of parallel information object search in unified information spaces consists of the following steps:

Step 1. The formation of unified information spaces takes place.

Step 2. In each formed unified information space, the process of eliminating duplicate information objects occurs, that is, each initial unified information space is rebuilt.

Step 3. There is a parallel process of comparing information objects in each unified information space with a certain incoming object $\mathrm{O}_{\mathrm{i}}$, which has a set of parameters $\left(\mathrm{P}_{1}, \mathrm{P}_{2}, \ldots, \mathrm{P}_{\mathrm{n}}\right)$.

If the value of each of this object parameters falls within the acceptable range of values for the corresponding feature of any information object from any unified information space $\left(M-D \leq P_{i} \leq M+D\right)$, then the incoming object is uniquely identified, that is, $\mathrm{O}_{\mathrm{i}}=\mathrm{UIS}_{\mathrm{i}}\left(\mathrm{IO}_{\mathrm{K}}\right)$.

Step 4. The missing features of the incoming object are clarified. If there are not enough features, then it is necessary to refer to other information objects of unified information spaces and request the necessary missing features based on the trajectory of information objects interaction with each other. For this, it is necessary that each information object retains the trajectory of interaction, that is, it actually has a kind of global memory. With this formation of a unified information space, all trajectories of all information objects interaction are placed in a single data warehouse.

Step 5. Displaying the found object, group of objects or stating the fact that the analyzed object is new and then it is placed in all unified information spaces.

\section{The Experimental Research}

Let us analyze the efficiency of incoming objects search in unified information spaces by the method of parallel information object search in unified information spaces.

For the experiments, 5 unified information spaces were formed from 20,000 information objects each.

The percentage of missing parameters in information objects (NONE) was 6\%.

A series of 100 experiments each was carried out, with certain probabilities $(5,10,15,20$ and $25 \%$, respectively) that the parameter would not be read by the sensors (NULL). 


\subsection{Experiment 1}

Let us consider the case when each of 20,000 information objects is described by 7 parameters in each of 5 unified information spaces. Below there is a fragment of 10 information objects from one of unified information spaces UIS ${ }_{2}$ :

$\begin{array}{lccccccc} & \text { P1 } & \text { P2 } & \text { P3 } & \text { P4 } & \text { P5 } & \text { P6 } & \text { P7 } \\ \text { IO1 } & 2 \pm 0,8 & 8 \pm 0,2 & 6 \pm 0,2 & 9 \pm 0,3 & 9 \pm 0,3 & 11 \pm 0,9 & 13 \pm 0,9 \\ \text { IO2 } & 5 \pm 0,2 & 5 \pm 0,4 & 4 \pm 0,9 & 5 \pm 0,5 & 8 \pm 0,2 & 12 \pm 0,5 & 9 \pm 0,9 \\ \text { IO3 } & 6 \pm 0,1 & 4 \pm 0,2 & 7 \pm 0,2 & \text { NONE } & 7 \pm 0,2 & 12 \pm 0,8 & 13 \pm 0,9 \\ \text { IO4 } & 1 \pm 0,7 & 8 \pm 0,9 & 8 \pm 0,5 & 8 \pm 0,5 & 11 \pm 0,3 & 8 \pm 0,2 & 11 \pm 0,3 \\ \text { IO5 } & 4 \pm 0,6 & 6 \pm 0,8 & 9 \pm 0,6 & 8 \pm 0,4 & 9 \pm 0,2 & 12 \pm 0,5 & 9 \pm 0,6 \\ \text { IO6 } & 2 \pm 0,4 & 4 \pm 0,6 & 4 \pm 0,5 & 8 \pm 0,4 & \text { NONE } & 9 \pm 0,1 & 12 \pm 0,6 \\ \text { IO7 } & 4 \pm 0,4 & 7 \pm 0,1 & 7 \pm 0,7 & 10 \pm 0,3 & 10 \pm 0,3 & 11 \pm 0,3 & 11 \pm 0,2 \\ \text { IO8 } & 1 \pm 0,8 & 6 \pm 0,8 & 3 \pm 0,8 & 4 \pm 0,6 & 11 \pm 0,4 & 11 \pm 0,9 & 13 \pm 0,8 \\ \text { IO9 } & 5 \pm 0,9 & 6 \pm 0,4 & 9 \pm 0,5 & 7 \pm 0,7 & 6 \pm 0,6 & 6 \pm 0,4 & 13 \pm 0,3 \\ \text { IO10 } & \text { NONE } & \text { NONE } & 5 \pm 0,8 & 9 \pm 0,8 & 11 \pm 0,7 & 11 \pm 0,2 & 9 \pm 0,5\end{array}$

In this case, the interval length for each parameter was 7 units, for example, for parameter P1[1; 7].

Then, in each unified information space, the process of eliminating duplicate information objects occurs, that is, each initial unified information space UIS $_{\text {reb }}$ is rebuilt. Execution time of this operation, for example, for the case when there are 7 parameters in each unified information space and the interval length of 7 units was 15.4 minutes, while the unique information objects in the first $\mathrm{UIS}_{\mathrm{reb} 1}$ remained -19886 , in the second $\mathrm{UIS}_{\mathrm{reb} 2}-19877$, in the third UIS $\mathrm{reb} 3_{-}$ 19874 , in the fourth UIS $_{\text {reb4 }}-19890$ and in the fifth UIS $_{\text {reb5 }}-19888$.

Generalization of the experiments results made it possible to conclude that the rebuilding time of 5 unified information spaces, depending on the interval length, is presented in Table 1.

Table 1. Rebuilding time of 5 unified information spaces, depending on the interval length of information objects

\begin{tabular}{|c|c|c|c|c|c|}
\hline \multirow{2}{*}{$\begin{array}{c}\text { Number of parameters, } \\
\text { units }\end{array}$} & \multicolumn{5}{|c|}{ Rebuilding time of 5 unified information spaces, minutes } \\
\cline { 2 - 6 } & \multicolumn{5}{|c|}{ Interval length, units } \\
\cline { 2 - 6 } & $\mathbf{3}$ & $\mathbf{4}$ & $\mathbf{3}$ & $\mathbf{6}$ & $\mathbf{3}$ \\
\hline 6 & 1,4 & 4,8 & 8,9 & 11,7 & 12,9 \\
\hline 7 & 3,8 & 9,6 & 11,5 & 14,7 & 15,4 \\
\hline 8 & 7,6 & 12,6 & 14,3 & 16,1 & 17,1 \\
\hline 9 & 11,2 & 14,8 & 15,8 & 17,7 & 18,5 \\
\hline 10 & 13,6 & 16,1 & 17,1 & 18,7 & 19,7 \\
\hline
\end{tabular}

1. When sensors read all the incoming object parameters values and its unique identification occurred:

New object:

$3 \pm 0,86 \pm 0,23 \pm 0,46 \pm 0,69 \pm 0,411 \pm 0,48 \pm 0,7$

Search object:

UIS1 $3 \pm 0,46 \pm 0,13 \pm 0,26 \pm 0,39 \pm 0,211 \pm 0,28 \pm 0,4$

2. When sensors read the incoming object parameters values and there was no identification, there was no information object in any of the five created unified information spaces that would describe this incoming object:

New object:

$2 \pm 0,88 \pm 0,28 \pm 0,610 \pm 0,15 \pm 0,9$ NONE $10 \pm 0,9$

Object absent!

3. When sensors did not read all incoming object parameters values (there are NULL values), but due to the interaction of information objects with each other in a unified information space, a unique incoming object identification took place:

New object:

$3 \pm 0,78 \pm 0,53 \pm 0,6$ Null $5 \pm 0,49 \pm 0,413 \pm 0,8$

Search object:

UIS3

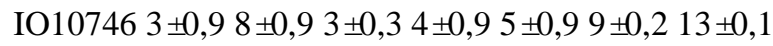

UIS4

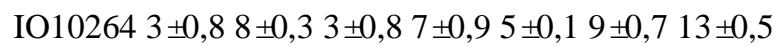

ReCreateObject:

$3 \pm 0,78 \pm 0,53 \pm 0,67 \pm 0,85 \pm 0,49 \pm 0,413 \pm 0,8$ 
Search object:

UIS4

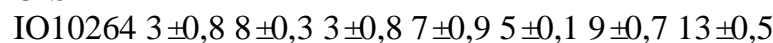

4. When the sensors read all incoming object parameters values and, despite the interaction of information objects with each other in a unified information space, incoming object identification did not occur:

New object:

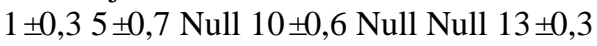

Search object:

UIS1

IO15664 $1 \pm 0,15 \pm 0,4$ None $10 \pm 0,210 \pm 0,86 \pm 0,913 \pm 0,9$

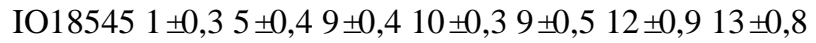

UIS2

IO1905 $1 \pm 0,35 \pm 0,85 \pm 0,910 \pm 0,98 \pm 0,3 \quad 12 \pm 0,513 \pm 0,1$

IO7619 1 $\pm 0,35 \pm 0,83 \pm 0,1 \quad 10 \pm 0,45 \pm 0,59 \pm 0,213 \pm 0,4$

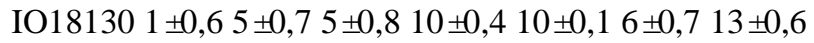

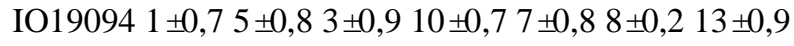

UIS3

IO3075 $1 \pm 0,35 \pm 0,63 \pm 0,7 \quad 10 \pm 0,210 \pm 0,2 \quad 12 \pm 0,3 \quad 13 \pm 0,6$

IO12233 $1 \pm 0,35 \pm 0,65 \pm 0,810 \pm 0,79 \pm 0,411 \pm 0,413 \pm 0,3$

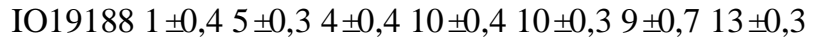

UIS4

IO5413 $1 \pm 0,45 \pm 0,24 \pm 0,8 \quad 10 \pm 0,1 \quad 11 \pm 0,2 \quad 8 \pm 0,1 \quad 13 \pm 0,9$

IO9332 $1 \pm 0,35 \pm 0,47 \pm 0,510 \pm 0,86 \pm 0,69 \pm 0,213 \pm 0,9$

IO11879 1 $1 \pm 0,15 \pm 0,44 \pm 0,510 \pm 0,1 \quad 10 \pm 0,912 \pm 0,413 \pm 0,6$

IO14071 $1 \pm 0,25 \pm 0,69 \pm 0,410 \pm 0,57 \pm 0,48 \pm 0,813 \pm 0,2$

IO15217 $1 \pm 0,25 \pm 0,24 \pm 0,310 \pm 0,111 \pm 0,96 \pm 0,413 \pm 0,5$

UIS5

IO8333 $1 \pm 0,25 \pm 0,76 \pm 0,3 \quad 10 \pm 0,25 \pm 0,3 \quad 12 \pm 0,913 \pm 0,7$

IO18619 1 $\pm 0,25 \pm 0,94 \pm 0,610 \pm 0,49 \pm 0,76 \pm 0,413 \pm 0,3$

IO19128 $1 \pm 0,45 \pm 0,55 \pm 0,210 \pm 0,210 \pm 0,37 \pm 0,813 \pm 0,9$

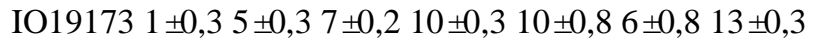

ReCreateObject:

$1 \pm 0,35 \pm 0,73 \pm 0,410 \pm 0,6$ Null Null $13 \pm 0,3$

Search object:

UIS2

IO7619 1 $1 \pm 0,35 \pm 0,83 \pm 0,110 \pm 0,45 \pm 0,59 \pm 0,213 \pm 0,4$

IO19094 $1 \pm 0,75 \pm 0,83 \pm 0,910 \pm 0,77 \pm 0,88 \pm 0,213 \pm 0,9$

UIS3

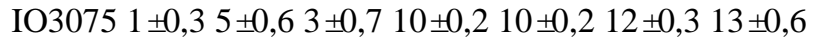

ReCreateObject:

$1 \pm 0,35 \pm 0,73 \pm 0,410 \pm 0,611 \pm 0,912 \pm 0,3 \quad 13 \pm 0,3$

Object absent!

Generalized results of the experiments allowed us to conclude about the efficiency of incoming objects search in unified information spaces with 7 parameters and an interval length of 7 units are presented in Table 2.

Table 2. Efficiency of incoming objects search in unified information spaces with 7 parameters and an interval length of 7 units

\begin{tabular}{|c|c|}
\hline $\begin{array}{c}\text { Probability that the parameter will not be read by } \\
\text { sensors (NULL), \% }\end{array}$ & $\begin{array}{c}\text { Probability of an incoming object } \\
\text { identification, \% }\end{array}$ \\
\hline 5 & 9 \\
\hline 10 & 8 \\
\hline 15 & 8 \\
\hline 20 & 6 \\
\hline 25 & 6 \\
\hline
\end{tabular}

Table 2 shows that the efficiency of incoming objects search in unified information spaces with 7 parameters and an interval length of 7 units is low.

Therefore, it was decided to reduce the number of parameters that describe the object and conduct similar 
experiments with 4, 5 and 6 parameters and the same initial data. The results of the experiments are presented in table 3.

Table 3. Efficiency of incoming objects search in unified information spaces with 4, 5 and 6 parameters and an interval length of 7 units

\begin{tabular}{|c|c|c|c|}
\hline \multirow{2}{*}{$\begin{array}{c}\text { Probability that the parameter will not be } \\
\text { read by sensors (NULL), \% }\end{array}$} & \multicolumn{3}{|c|}{ Probability of an incoming object identification, \% } \\
\cline { 2 - 4 } & $\mathbf{4}$ & $\mathbf{5}$ & $\mathbf{4}$ \\
\cline { 2 - 4 } & 100 & 98 & 54 \\
\hline 5 & 100 & 100 & 42 \\
\hline 10 & 100 & 98 & 43 \\
\hline 15 & 100 & 97 & 46 \\
\hline 20 & 100 & 99 & 42 \\
\hline 25 & & & \\
\hline
\end{tabular}

Table 3 shows that the probability of an incoming object identification in unified information spaces with 4 parameters and an interval length of 7 units is equal to $100 \%$, that is, it makes no sense to further reduce the number of parameters.

Time during which 100 experiments were carried out with 4, 5, 6 and 7 parameters and an interval length of 7 units are presented in table 4 .

Table 4. Time during which 100 experiments were carried out with 4, 5, 6 and 7 parameters and an interval length of 7 units

\begin{tabular}{|c|c|c|c|c|c|}
\hline \multirow{2}{*}{$\begin{array}{c}\text { Number of } \\
\text { parameters, units }\end{array}$} & \multicolumn{5}{|c|}{ Time, $\mathbf{5}$} \\
\cline { 2 - 6 } & \multicolumn{4}{|c|}{ Probability that the parameter will not be read by sensors (NULL), \% } \\
\cline { 2 - 6 } & $\mathbf{5}$ & $\mathbf{1 0}$ & $\mathbf{5}$ & $\mathbf{2 0}$ & $\mathbf{5}$ \\
\hline 4 & 10,9 & 13,2 & 14,8 & 21,4 & 34,3 \\
\hline 5 & 11,1 & 18,2 & 18,8 & 23,3 & 40,7 \\
\hline 6 & 12,5 & 17,7 & 22,6 & 29,3 & 34,7 \\
\hline 7 & 16,1 & 18 & 22,7 & 36,3 \\
\hline
\end{tabular}

Based on the data in Tables 2 and 4, a graph was constructed for comparing the efficiency of incoming objects search in unified information spaces with 4, 5, 6 and 7 parameters and an interval length of 7 units (Fig. 3).

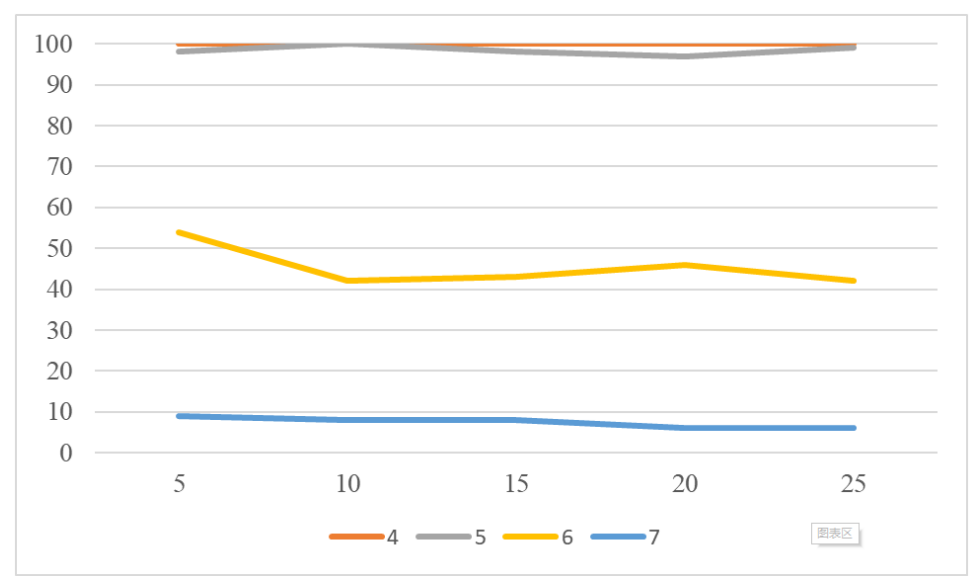

Fig.3. Comparative graph of the efficiency of incoming objects search in unified information spaces with 4, 5, 6 and 7 parameters and an interval length of 7 units

From Figure 3, we can conclude that the efficiency of incoming objects search in unified information spaces with an interval length of 7 units was on average the following: with 4 parameters $-100 \%$, with 5 parameters $-98,4 \%$, with 6 parameters $-45,4 \%$, and with 7 parameters $-7,4 \%$.

Based on the data in Table 4, a graph was drawn for comparing the incoming objects search time in unified information spaces with 4, 5, 6 and 7 parameters and an interval length of 7 units (Fig. 4). 


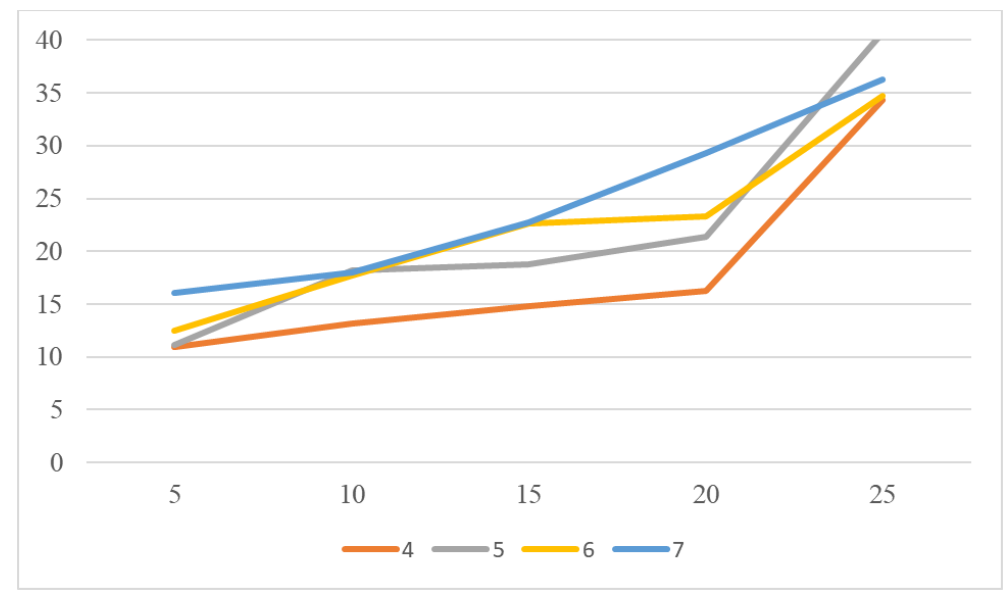

Fig.4. Comparative graph of the incoming objects search time in unified information spaces with 4, 5, 6 and 7 parameters and an interval length of 7 units

From Figure 4, it can be concluded that the incoming objects search time in unified information spaces with an interval length of 7 units was on average the following: with 4 parameters $-17,9$ s, with 5 parameters $-22,04$ s, with 6 parameters $-22,16 \mathrm{~s}$, and with 7 parameters $-24,48 \mathrm{~s}$.

It follows from the above that a decrease in the number of parameters leads to a sharp increase in the efficiency of incoming objects search in unified information spaces.

\subsection{Experiment 2}

When analyzing the conclusions made after experiment 1, it was decided to increase the interval length of incoming objects parameter values in unified information spaces to 8 units.

Let us consider the case when each of 20,000 information objects is described by 4, 5, 6, and 7 parameters with an interval length of 8 units in each of 5 unified information spaces. The results of the experiments are presented in table 5.

Table 5. Efficiency of incoming objects search in unified information spaces with 4, 5, 6 and 7 parameters and an interval length of 8 units.

\begin{tabular}{|c|c|c|c|c|c|}
\hline \multirow{2}{*}{$\begin{array}{c}\text { Number of } \\
\text { parameters, units }\end{array}$} & \multicolumn{5}{|c|}{ Probability of an incoming object identification, \% } \\
\cline { 2 - 6 } & $\mathbf{5}$ & $\mathbf{1 0}$ & $\mathbf{5}$ & $\mathbf{2 0}$ & 100 \\
\hline 4 & 100 & 100 & 100 & 95 & 100 \\
\hline 5 & 90 & 85 & 84 & 28 & 86 \\
\hline 6 & 26 & 29 & 29 & 3 & 27 \\
\hline 7 & 3 & 5 & 3 & & 4 \\
\hline
\end{tabular}

Based on the data in Table 5, a graph was constructed for comparing the efficiency of incoming objects search in unified information spaces with 4, 5, 6 and 7 parameters and an interval length of 8 units (Fig. 5).

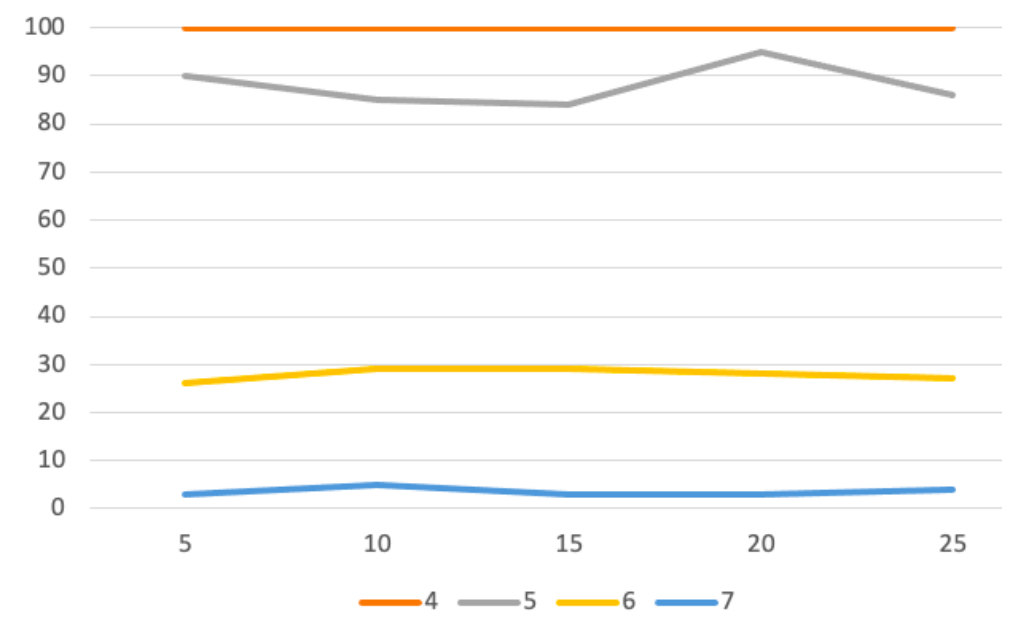

Fig.5. Comparative graph of incoming objects search efficiency in unified information spaces with 4, 5, 6 and 7 parameters and an interval length of 8 units 
From Figure 5, we can conclude that the efficiency of incoming objects search in unified information spaces with an interval length of 8 units on average was the following: with 4 parameters $-100 \%$, with 5 parameters $-88 \%$, with 6 parameters $-27,8 \%$ and with 7 parameters $-3,6 \%$.

It follows from this that an increase in the interval length leads to a decrease in the efficiency of incoming objects search in unified information spaces.

\subsection{Experiment 3}

When analyzing the conclusions made after experiment 2 , it was decided to conduct similar experiments at smaller values of intervals lengths of information objects parameters.

Let us consider the case when each of 20,000 information objects is described by 7 parameters with the interval length of 3, 4, 5 and 6 units in each of 5 unified information spaces. The results of the experiments are presented in table 6 .

Table 6. Efficiency of incoming objects search in 5 unified information spaces with 7 parameters and interval lengths of 3, 4, 5 and 6 units

\begin{tabular}{|c|c|c|c|c|c|}
\hline \multirow{2}{*}{$\begin{array}{c}\text { Interval length, } \\
\text { units }\end{array}$} & \multicolumn{5}{|c|}{ Probability of an incoming object identification, \% } \\
\cline { 2 - 6 } & $\mathbf{5}$ & $\mathbf{1 0}$ & $\mathbf{5}$ & $\mathbf{2 0}$ & 100 \\
\cline { 2 - 6 } & 100 & 100 & 100 & 95 & 100 \\
\hline 3 & 99 & 98 & 96 & 64 & 93 \\
\hline 4 & 57 & 51 & 63 & 22 & 61 \\
\hline 5 & 22 & 22 & 8 & 6 & 6 \\
\hline 6 & 9 & 8 & & 6 \\
\hline
\end{tabular}

Based on the data in Table 6, a graph was constructed for comparing the efficiency of incoming objects searching in unified information spaces with 7 parameters and interval lengths of 3, 4, 5 and 6 units (Fig. 6).

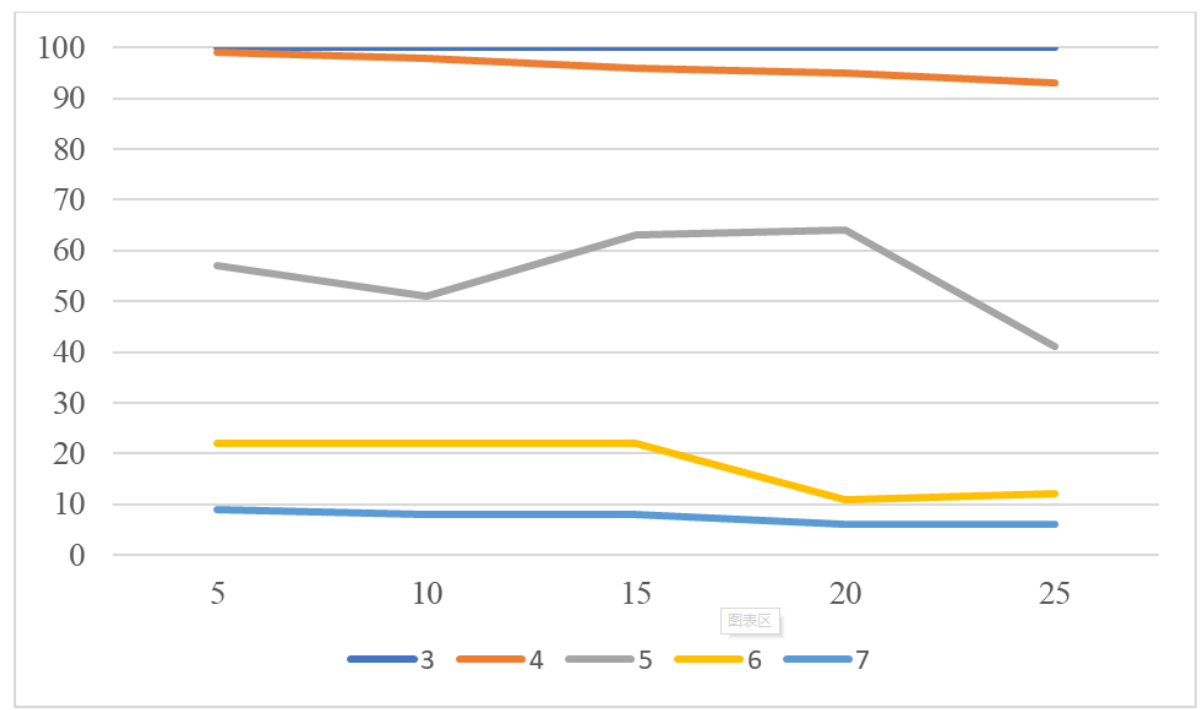

Fig.6. Comparative graph of incoming objects search efficiency in unified information spaces with 7 parameters and interval lengths of $3,4,5$ and 6 units

From Figure 6, we can conclude that incoming objects search efficiency in unified information spaces with 7 parameters and interval lengths of 3, 4, 5 and 6 units on average was the following: with an interval length of 3 units $100 \%$, with an interval length of 4 units $-96,2 \%$, with an interval length of 5 units $-55,2 \%$, with an interval length of 6 units $-17,8 \%$ and with an interval length of 7 units $-7,4 \%$.

Summarizing the results of the above experiments, we present the average search efficiency for incoming objects in unified information spaces with 6, 7, 8, 9 and 10 parameters and interval lengths of 3, 4, 5, 6, 7 and 8 units (Table 7). 
Table 7. Average search efficiency of incoming objects in unified information spaces with 6,7,8,9 and 10 parameters and interval lengths of $3,4,5$, 6,7 and 8 units

\begin{tabular}{|c|c|c|c|c|c|c|}
\hline \multirow{2}{*}{$\begin{array}{c}\text { Number of } \\
\text { parameters, units }\end{array}$} & \multicolumn{7}{|c|}{ Average probability of an incoming object identification, \% } \\
\cline { 2 - 7 } & $\mathbf{3}$ & $\mathbf{4}$ & $\mathbf{3}$ & $\mathbf{6}$ & $\mathbf{3}$ & $\mathbf{8}$ \\
\cline { 2 - 7 } & $\mathbf{3}$ & 100 & 97,2 & 78 & 45,4 & 27,8 \\
\hline 6 & 100 & 96,2 & 55,2 & 17,8 & 7,4 & 3,6 \\
\hline 7 & 100 & 59,6 & 15 & 3,8 & 0,4 & 0,6 \\
\hline 8 & 98,4 & 18,6 & 2,4 & 0,8 & 0,2 & 0 \\
\hline 9 & 92,6 & 6,8 & 0,4 & 0 & 0 & 0 \\
\hline 10 & 54,2 & & & & & 0 \\
\hline
\end{tabular}

Based on the data in Table 7, a graph was constructed for comparing the average search efficiency of incoming objects in unified information spaces with $6,7,8,9$ and 10 parameters and interval lengths of 3, 4, 5, 6, 7 and 8 units (Fig. 7).

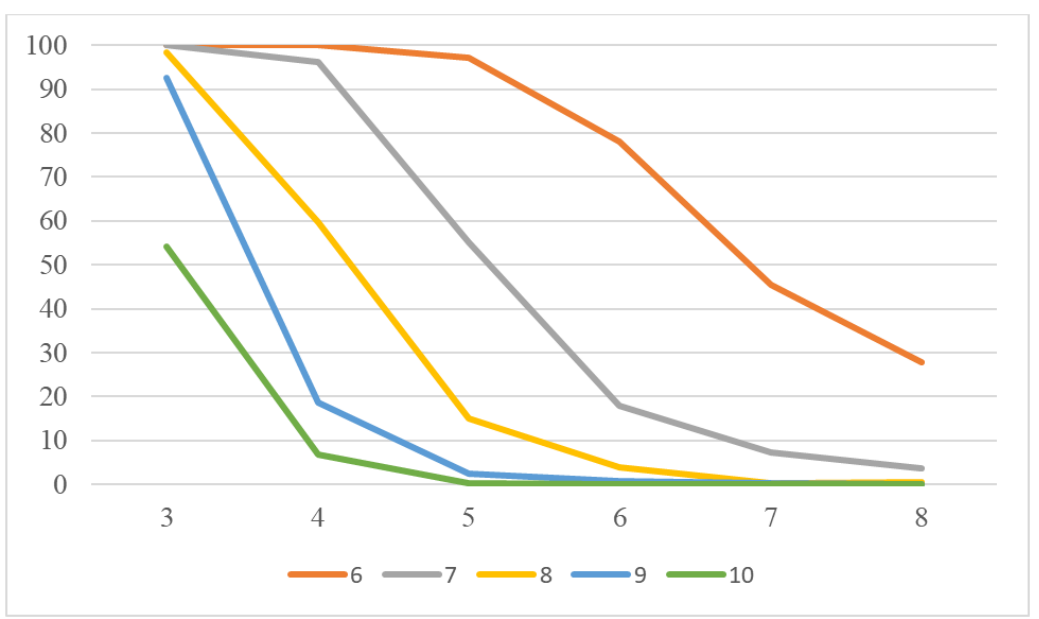

Fig.7. Comparative graph of average search efficiency of incoming objects in unified information spaces with 6, 7, 8, 9 and 10 parameters and interval lengths of $3,4,5,6,7$ and 8 units

From Figure 7, we can conclude that incoming objects search efficiency in single information spaces, on average, was:

1) with 6 parameters $-74,73 \%$, with 7 parameters $-46,70 \%$, with 8 parameters $-29,63 \%$, with 9 parameters $19,10 \%$ and with 10 parameters $-10,23 \%$.

2) with an interval length of 3 units $-89,04 \%$, with an interval length of 4 units $-56,24 \%$, with an interval length of 5 units $-34,04 \%$, with an interval length of 6 units $-20,08 \%$, with an interval length of 7 units $-10,68 \%$ and with an interval length of 8 units $-6,4 \%$.

Based on the above experiments, we present average search time for incoming objects in unified information spaces with 6, 7, 8, 9 and 10 parameters and interval lengths of 3, 4, 5, 6, 7 and 8 units (Table 8).

Table 8. Average search time for incoming objects in unified information spaces with 6, 7, 8, 9 and 10 parameters and interval lengths of 3, 4, 5, 6, 7 and 8 units

\begin{tabular}{|c|c|c|c|c|c|c|}
\hline \multirow{2}{*}{$\begin{array}{c}\text { Number of } \\
\text { parameters, units }\end{array}$} & \multicolumn{7}{|c|}{ Average time of an incoming object identification, $\mathbf{c}$} \\
\cline { 2 - 7 } & \multicolumn{7}{|c|}{ Interval length, units } & $\mathbf{3}$ & $\mathbf{8}$ \\
\cline { 2 - 7 } & $\mathbf{3}$ & $\mathbf{4}$ & $\mathbf{3}$ & $\mathbf{6}$ & $\mathbf{3}, 32,16$ & 25,86 \\
\hline 6 & 18,32 & 25,62 & 21,8 & 22,36 & 24,48 & 27,44 \\
\hline 7 & 25,08 & 26,86 & 24,6 & 26,46 & 26,28 & 27,6 \\
\hline 8 & 29,9 & 29,68 & 29,96 & 30,2 & 29,46 & 30,58 \\
\hline 9 & 31,22 & 34,22 & 31,7 & 35,46 & 33,14 & 36,2 \\
\hline 10 & 37,36 & 33,86 & 35,36 & & & \\
\hline
\end{tabular}

Based on the data in Table 8, a graph was made for comparing average search time for incoming objects in unified information spaces with 6, 7, 8, 9 and 10 parameters and interval lengths of 3, 4, 5, 6, 7 and 8 units (Fig. 8). 


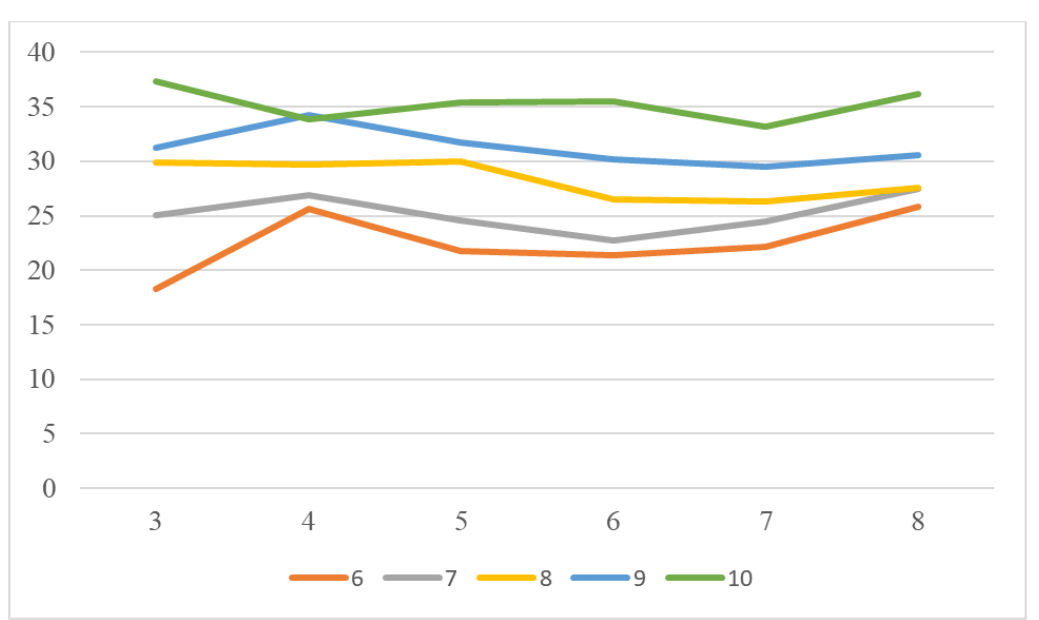

Fig.8. Graph of the average search time for incoming objects in unified information spaces with 6, 7, 8, 9 and 10 parameters and interval lengths of 3 , $4,5,6,7$ and 8 units

From Figure 8, we can conclude that the average search time for incoming objects in single information spaces was:

1) with 6 parameters $-22,52 \mathrm{~s}$, with 7 parameters $-25,19 \mathrm{~s}$, with 8 parameters $-28,31 \mathrm{~s}$, with 9 parameters $-31,23 \mathrm{~s}$ and with 10 parameters $-35,23 \mathrm{~s}$.

2) with an interval length of 3 units $-28,38 \mathrm{~s}$, with an interval length of 4 units $-30,05 \mathrm{~s}$, with an interval length of 5 units $-28,68$ s, with an interval length of 6 units $-27,24$ s, with an interval length of 7 units $-27,10$ s and with an interval length of 8 units $-29,54 \mathrm{~s}$.

In the future, in order to perform a qualitative analysis according to the criteria of efficiency and search time for an incoming object, we plan to develop a method based on combination of the information spaces into an intermediate unified information space for unambiguous identification of an incoming object.

\section{Conclusions}

1. Described the concept of a single information space and an algorithm for its formation using a special information and computer system. The process of identifying an information object in a single information space is considered, which makes it possible to uniquely identify it according to corresponding features.

2. The method of parallel information object search in single information spaces is proposed, when information object search will be conducted independently in parallel in all single information spaces.

3. Based on the results of the experiments, the following conclusions can be drawn:

- the incoming objects search efficiency in unified information spaces tends to a direct proportion with a decrease in the interval length and an increase in the number of parameters, and vice versa;

- as a result, it was experimentally found that the more parameters that describe the information object, the less the object identification time depends on the interval length.

\section{References}

[1] Mayorov, A. (2015). Information objects in the information field. Educational Resources and Technologies, (1 (9)), 66-73.

[2] Kastornova, V.A (2012). Unified information educational space and its components. Bulletin of Cherepovets State University, 1 (3 (40)), 109-112.

[3] Yakushenko, KV (2014). Unified information space: theoretical approaches to the content of the concept. Belarus and world economic processes: Sat. scientific Art. Issue. 11. - Minsk, 2014. - P.13-20

[4] Gershkovich M., Biryukova, T. Problems of Identification of Information Objects in Distributed Data Arrays, Systems and Means of Inform., 2014, Volume 24, Issue 1, 224-243. DOI: https://doi.org/10.14357/08696527140114

[5] Basic principles of creating a single information space of corporate systems / Yu.G. Pilipenko // Mat. machines and systems. 2006. - № 4. - P. 124-128.

[6] Vincent, AV (2011). Development of a model of a single information space to assess the reliability of its operation. Proceedings of the Kola Scientific Center of the Russian Academy of Sciences, (7), 65-70.

[7] Dodonov, A., Mukhin, V., Zavgorodnii, V., Kornaga, Ya., Zavgorodnya A. (2021). Method of searching for information objects in unified information space. System research and information technologies, N1, pp. 34-46. doi: https://doi.org/10.20535/SRIT.2308-8893.2021.1.03

[8] Yalova, K., Zavgorodnii, V., Romanyukha, M., \& Sorokina, L. (2016). Challenges and prospects in development of e-learning system for IT students. International Journal of Continuing Engineering Education and Life Long Learning, 26(1), 25-43. 
https://doi.org/10.1504/IJCEELL.2016.075042

[9] Mukhin, V., Zavgorodnii, V., Barabash, O., Mykolaichuk, R., Kornaga, Y., Zavgorodnya, A., \& Statkevych, V. (2020). Method of Restoring Parameters of Information Objects in a Unified Information Space Based on Computer Networks. International Journal of Computer Network and Information Security, Vol.12, No.2, pp.11-21, 2020. DOI: 10.5815/ijcnis.2020.02.02

[10] Mukhin V., Kornaga Y., Zavgorodnii V., Zavgorodnya A., Herasymenko O., Mukhin O. (2019) Social Risk Assessment Mechanism Based on the Neural Networks. International Conference on Advanced Trends in Information Theory (ATIT-2019). 18-20 December 2019. P. 179-182. DOI: 10.1109/ATIT49449.2019.9030519

[11] Smelyakov K., Ruban I., Sandrkin D., Martovytskyi V., and Romanenkov Y. (2018) "Search by Image. New Search Engine Service Model" 2018 5th International ScientificPractical Conf. Problems of Infocommunications. Science and Technology (PIC S\&T), 9-12, 2018, pp. 181-186.

[12] Bielievtsov S., Ruban I., Smelyakov K., and Sumtsov D. (2018) , "Network technology for transmission of visual information," Selected Papers of the XVIII Intern. Scientific and Practical Conf. on Information Technologies and Security (ITS 17.05.2018). - CEUR Workshop Proc., Kyiv, Ukraine, Nov. 27, 2018, pp. 160-175.

[13] Z. Hu, V. Mukhin, Ya. Kornaga, O. Herasymenko and Ye. Mostoviy (2019), "The Analytical Model for Distributed Computer System Parameters Control Based on Multi-factoring Estimations", Journal of Network and Systems Management, vol. 27, no. 2, pp. 351-365, 2019.

[14] Mukhin, V., Volokyta, A., Heriatovych, Y., Rehida, P. (2018) Method for efficiency increasing of distributed classification of the images based on the proactive parallel computing approach.// Advances in Electrical and Computer Engineering, 2018, $18(2)$, pp. $117-122$.

[15] Elie Tagne Fute, Doris-Khöler Nyabeye Pangop, Emmanuel Tonye, (2020) "A Hybrid Approach for the Multisensor Patrolling Problem in an Unknown Environment with Obstacles", International Journal of Computer Network and Information Security(IJCNIS), Vol.12, No.5, pp.16-30, 2020. DOI: 10.5815/ijcnis.2020.05.02

[16] Essaid EL HAJI, Abdellah Azmani, (2020) "Proposal of a Digital Ecosystem Based on Big Data and Artificial Intelligence to Support Educational and Vocational Guidance", International Journal of Modern Education and Computer Science (IJMECS), Vol.12, No.4, pp. 1-11, 2020.DOI: 10.5815/ijmecs.2020.04.01

[17] Nikolay Karabutov, "Structural Identifiability of Nonlinear Dynamic Systems under Uncertainty", International Journal of Intelligent Systems and Applications (IJISA), Vol.12, No.1, pp.12-22, 2020. DOI:10.5815/ijisa.2020.01.02

[18] D. Asir Antony Gnana Singh, E. Jebamalar Leavline, "Dimensionality Reduction for Classification and Clustering", International Journal of Intelligent Systems and Applications (IJISA), Vol.11, No.4, pp.61-68, 2019. DOI: 10.5815/ijisa.2019.04.06

\section{Authors' Profiles}

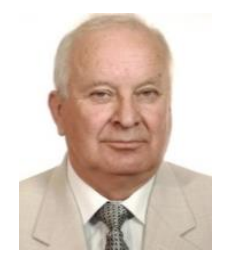

Alexander Dodonov: Deputy Director for Scientific Research Institute of Problems of Information Registration of the National Academy of Sciences of Ukraine, Doct. of Sc., Professor, Honored worker of science and technology of Ukraine

Major interests: theoretical bases and applied methods of creation of computer information-analytical systems; research and development of methods of information security in computer systems and networks; methods and systems of decision support; theoretical foundations and applied methods of computer simulation.

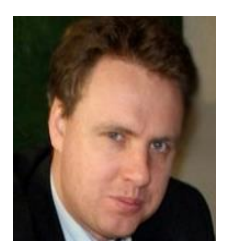

Vadym Mukhin: Professor of department of the mathematical methods of system analysis of National Technical University of Ukraine "Kiev Polytechnic Institute", Doct. of Sc.

Born on November 1, 1971. M. Sc. (1994), PhD (1997), Doct. of Sc. (2015) from the National Technical University of Ukraine "Kiev Polytechnic Institute"; Professor (2015).

Major interests: the security of distributed computer systems and risk analysis; design of the information security systems; mechanisms for the adaptive security control in distributed computing systems; the security policy development for the computer systems and networks.

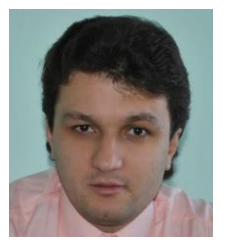

Valerii Zavgorodnii: Assoc. professor of Department of Information Technologies and Design of the State University of Infrastructure and Technologies, $\mathrm{PhD}$.

Born on May 25, 1982. PhD (2013) from Kremenchuk Mykhailo Ostrohradskyi National University; Assoc. Prof. (2015) of Department of Systems Software.

Major interests: information technologies, databases, decision support systems, introduction of Information and communication technology in the educational process. 


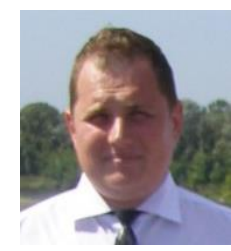

Yaroslav Kornaga: Assoc. professor of computer systems department of National Technical University of Ukraine "Kiev Polytechnic Institute", PhD.

Born on January 1, 1982. M. Sc. (2005), PhD (2015), Doct. of Sc. (2020) from State University of Telecommunications; Assoc. Prof. (2015) of technical cybernetics department.

Major interest: the security of distributed database and risk analysis; design of the distributed database; mechanisms for the adaptive security control in distributed database; the security policy development for distributed database.

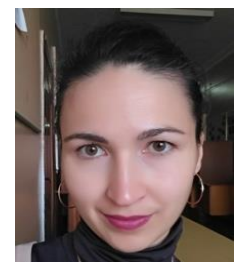

Anna Zavgorodnya: Assoc. professor of Department of Information Technologies and Design of the State University of Infrastructure and Technologies.

Born on January 12, 1989. M. Sc. (2011). PhD (2020) from West Ukrainian National University.

Major interest: software engineering, databases, information systems, business process management.

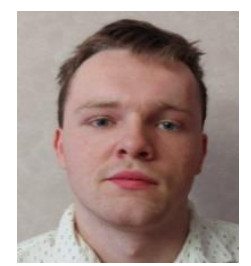

Oleg Mukhin: Student of department of the mathematical methods of system analysis of National Technical University of Ukraine "Kiev Polytechnic Institute"

Major interests: the applied software for the computer systems and networks.

How to cite this paper: Alexander Dodonov, Vadym Mukhin, Valerii Zavgorodnii, Yaroslav Kornaga, Anna Zavgorodnya, Oleg Mukhin, "Method of Parallel Information Object Search in Unified Information Spaces", International Journal of Computer Network and Information Security(IJCNIS), Vol.13, No.4, pp.1-13, 2021. DOI: 10.5815/ijcnis.2021.04.01 